\title{
Personality Characteristics in Migraine and Tension Type Headache
}

\author{
Sadeghali Taziki ${ }^{1}$, Sharareh Saghafi ${ }^{1^{*}}$, Davood Fathi ${ }^{2,3,4}$ and Azadeh Ramezannezhad ${ }^{5}$ \\ ${ }^{1}$ Golestan Research Center of Psychiatry, Golestan University of Medical Sciences, Gorgan, Iran \\ ${ }^{2}$ Brain and Spinal Cord Injury Research Center, Tehran University of Medical Sciences, Tehran, Iran \\ 3 International Neuroscience Institute, Hannover, Germany \\ ${ }^{4}$ Neuroscience Institute, Tehran University of Medical Sciences, Tehran, Iran \\ ${ }^{5}$ Gorgan Medical Faculty, Golestan University of Medical Sciences, Gorgan, Iran
}

"Corresponding author: Sharareh Saghafi, General Physician, Research fellow, No 88, Research Centers Building, Azar 10 alley, 5 th Azar Street, Gorgan, Iran, Tel: 00981712325581; Fax:00981712325581; E-mail: Drshsaghafi@gmail.com.

Received date: January 29, 2014, Accepted date: July28, 2014, published date: August 5, 2014

Copyright: () 2014 Sharareh Saghafi et al., This is an open-access article distributed under the terms of the Creative Commons Attribution License, which permits unrestricted use, distribution, and reproduction in any medium, provided the original author and source are credited.

\section{Abstract}

Introduction: Headache is one the most common nuisances known to men. About $65 \%$ of patients seen in headache clinics suffer from migraine, $25 \%$ from tension type headache and about $10 \%$ from other types of headaches. Most people experience mood and behavior changes as accompanying feature during a headache attack.
\end{abstract}

Objectives: This study aimed to investigate the different types of personality characteristics in patients with migraine and tension type headache.

Methods: In a cross sectional study, all neurology and psychiatry outpatients of 5thAzar clinics of Gorgan, referred with chief complaint of headache were examined during 2007-2008. Patients with a final diagnosis of migraine or tension type headache were included. They filled short form of Minnesota Multiphasic Personality Inventory (MMPI).

Results: From 160 patients, 148 (92.5\%) were women and 12(7.5\%) were men. 96 patients (60\%) had tension type headache and $64(41.2 \%)$ had migraine.

In tension type headache, depressed personality (43.8\%) and hysterical personality (16.4\%) were more common, but in migraine group, depressed personality (48.9\%) and paranoid personality (20\%) had higher frequency.

There was a significant difference between higher versus lower education and showing depression in MMPI $(P=0.04)$

Psychopath deviation showed in $10(6.76 \%)$ female and $3(33.33 \%)$ male $(P=0.02)$

Mean age $\pm S D$ was $34.94 \pm 11.92$ in tension type headache group and it was $31.01 \pm 10.07$ in the migraine group $(P=0.03)$.

Conclusion: The higher prevalence of depressed personality type in both migraine and tension type headache may increase the attention to these patients about their future possibility of depression and preventive cares.

Keywords: Tension type Headache; Migraine, Personality characteristic; MMPI

\section{Introduction}

Headache is one of the most common disorders of the nervous system. Its several subtypes such as tension type headache, migraine and cluster headache cause substantial levels of disability. Yet, throughout the world, headache has been and continues to be underestimated in scope and scale, and headache disorders remain under-recognized and under-treated everywhere [1]. Migraine is a common neurological disorder with a prevalence of approximately $12 \%$, and a cause of significant disability for many patients [2-7]. As a result, the World Health Organization has listed migraine as a significant public health concern and a major cause of years of life lived with disability $[8,9]$. Tension type headache is the most frequent type of primary headache disorder in the general population with a prevalence of about $42 \%$ of adult patients. It has a major impact on patient's job performance and quality of life, leading to an economic burden on society [10]. Numerous studies have examined the personality structure of patients with primary headache disorders, and it has been found that such patients were mildly anxious and depressed relative to their headache free counterparts [11-13]. These patients have generally experienced more adverse events and rated them as more stressful than did headache free volunteers [14]. A high level of anxiety, neuroticism, or depression has also been found in 
patients with this headache type [12]. These patients present a significant impairment of anger control, a higher level of anxiety, depression, phobias and obsessive compulsive symptoms, emotional liability, and psychophysiological disorders, thus suggesting a connection between anger and duration of headache experience [15].

The importance of personality traits in migraine has been widely debated. Claims have been made that migraineurs display increased neuroticism and anxiety and are anti-aggressive, but complex interactions regarding personality traits need to be considered [16,17]. It may be that some of these personality traits also could be an effect of serious and insufficiently processed life events, as it is shown that migraine patients may have a history of maltreatment, especially during childhood [18-20].

Minnesota Multiphasic Personality Inventory (MMPI) is the most popular assessment instrument used to investigate personality traits $[21,22]$. The Mini-Mult MMPI-71 has generated an appreciable amount of research related to its utility with a variety of clinical population [22-25]. This study aimed to investigate the different types of personality characteristics in patients with migraine and tension type headache with short edition of MMPI.

\section{Material and Methods}

The subjects were all neurology and psychiatry outpatients with chief complaint of headache who had been referred to 5thAzar clinics of Gorgan, the capital city of Golestan province in Iran during 2007-2008. The diagnosis of migraine and tension type headache was made by means of face to face clinical interview by a neurologist or psychiatrist using the International Headache Society (2nd edition, IHS-II; 2004) criteria [26]. The patients who had any known medical condition, other psychiatric problems, or have been treated for the headache before, were excluded.

After an explanation of the confidentiality of the data, the patients were visited by a general physician and demographic data were collected from which volunteers were accepted for the research. Each subject indicated his response on an individual sheet of paper. The Mini-Mult MMPI-71 is an abbreviated form of the MMPI. This 71- item short form provides conversion tables for deriving raw scores for three validity scales and eight clinical scales (scales MF and SI were omitted). The standard booklet form of the normalized Persian version of the Mini-Mult MMPI-71 was completed by each subject at the first session of admission when subjects were free from drug effects or withdrawal symptoms and score of cognitive function was higher than 25 on the mini-mental status examination[27].

The reading level of the subjects was sixth grade or higher. Predicted row scores for the three validates and eight clinical scale of the MMPI were obtained from Armentrout's (and Rouzer's) recommendation, who defined technically invalid as either $\mathrm{L}, \mathrm{F}$, or $\mathrm{K}, \mathrm{T}$ scores of above 70 [28].

Statistical analysis was done by chi-square test using the Statistical Package for Social Sciences version 16.0 software (SPSS Inc, Chicago, IL, USA) and a p-value of less than 0.05 was deemed statistically significant.

\section{Results}

From 160 eligible patients were included, 148 patients (92.5\%) were women and $12(7.5 \%)$ were men. 64 patients $(40.0 \%)$ had migraine and 96 patients $(60.0 \%)$ had tension type headaches. The migraineurs had migraine without aura and the patients with tension type headache had frequent episodic tension type headache using the International Headache Society (2nd edition, IHS-II; 2004) criteria[26].

Mean \pm SD of age was lower $(31.02 \pm 10.07$; range $18-55$ years $)$ in migraine group than (34.94 \pm 11.92 years; range 18-60) in tension type headache group $(\mathrm{P}=0.03)$. Out of 160 patients, 98 (61.2\%) didn't finish high school education. 39 of them (39.8\%) showed depression trait in MMPI versus those who finished high school education (15 from 62; 24.2\%) $(\mathrm{P}=0.04)$.

There was no significant difference between migraine and tension type headache in male and female gender. Also, either of migraine and tension type groups didn't have significant difference in having abnormal personality traits, overall. Frequency of different types of personality traits in headache groups has been showed in Table 1.

\begin{tabular}{|c|c|c|c|c|c|c|c|c|c|c|c|}
\hline \multicolumn{3}{|l|}{ Type } & $\begin{array}{l}\text { Hypochond } \\
\text { rias is }\end{array}$ & Depression & $\begin{array}{l}\text { Psychopat } \\
\text { h Deviation }\end{array}$ & Paranoia & $\begin{array}{l}\text { Psychasth } \\
\text { enia }\end{array}$ & $\begin{array}{l}\text { Schizophre } \\
\text { nia }\end{array}$ & Normal & Guard & Total \\
\hline \multirow{4}{*}{ Headache } & \multirow{2}{*}{ Migraine } & $N$ & 5 & 22 & 3 & 9 & 6 & 0 & 16 & 3 & 64 \\
\hline & & $\%$ & 7.7 & 34.4 & 4.7 & 14.1 & 9.4 & 0 & 25.0 & 4.7 & 100.0 \\
\hline & \multirow{2}{*}{ Tension } & $\mathrm{N}$ & 12 & 32 & 10 & 8 & 9 & 2 & 22 & 1 & 96 \\
\hline & & $\%$ & 12.6 & 33.3 & 10.4 & 8.3 & 9.4 & 2.1 & 22.9 & 1.0 & 100.0 \\
\hline \multirow{2}{*}{ Total } & & $\mathrm{N}$ & 17 & 54 & 13 & 17 & 15 & 2 & 38 & 4 & 160 \\
\hline & & $\%$ & 10.6 & 33.8 & 8.1 & 10.6 & 9.4 & 1.2 & 23.8 & 2.5 & 100 \\
\hline \multicolumn{3}{|l|}{ PValue } & 0.35 & 0.89 & 0.19 & 0.25 & 1.00 & 0.24 & 0.76 & 0.15 & 0.43 \\
\hline
\end{tabular}

Table 1: Personality traits in headache groups

$6.8 \%$ of females $(\mathrm{N}=10)$ and $25.0 \%$ of males $(\mathrm{N}=3)$ showed psychopath deviation $(\mathrm{P}=0.03)$. Maybe this result caused by low number of our male subjects.
Mean \pm SD of age in schizophrenia trait was $41.00 \pm 0.00$ versus others $(33.27 \pm 11.39)$. There was a significant association between higher age and schizophrenia trait $(\mathrm{P}<0.005)$. 
From all subjects 4 (2.5\%) were in guard group according to L, F and $\mathrm{K}$ scale score over 70 . Mean \pm SD of age in guard group was 25.25 \pm 4.86 . There was a significant association between lower age and showing guard group scales $(\mathrm{P}=0.03)$.

\section{Discussion}

The literature on personality characteristics and headache still poses considerable discrepancies, with regard to both the eventual pathogenic role of personality characteristics and possible association between certain personality traits and migraine [29]. "Migraine personality" defined as a characteristic set of psychological features that was found among adult migraine sufferers [30]. More recent population based studies have demonstrated bi-directional associations between migraine and depression and migraine with panic disorder [31,32]. Some previous studies found significant difference between migraine patients than normal control groups on different personality traits [29]. Some studies showed that persons with chronic tension type headache had a significantly higher neuroticism score and a significantly higher level of psychological distress than the general population. Headache or medication days per month had no significant influence on the neuroticism [33]. In our study there was no significant difference between different personality traits and migraine and tension type headache patients. Females were not different in any kind of personality traits compared to their male counterparts. But male subjects showed significantly higher scores in psychopath deviation trait. That maybe because of our little male subject numbers and should be assessed in a more equal sample in the future. In a Turkish study, tension type headache group got significantly higher scores on neurotic subtests (Hypochondriasis, depression, hysteria) than subjects in the control group. Likewise, migraine subjects got significantly higher scores on hysteria subtest than control subjects. No significant differences were noted between migraine and tension type groups. However, none of the headache groups could be characterized by marked elevations on any of the validity and clinical scales [21]. In our study also, migraine and tension type headache group didn't show any significant difference that supports these findings. In another study in Germany, there were no statistically significant differences between the headache groups. It was impossible to distinguish headache groups on the basis of their personality profiles by means of reclassification with discriminate analysis [34].

Our study showed a significant difference in mean of age between migraine and tension type headache groups. In another study in USA, suggested specific age differences in migraineurs, in the most instances shows an age decline in frequency of variables, such as stress trigger, photophobia, dizziness, throbbing, pressure, stabbing, and being forced to sleep or rest with headache. Hormones as a trigger peaked in women in the 30 to 49 year old age group. Increases with age were seen with alcohol, smoke, and neck pain triggers, neck location, and running of the nose/tearing of the eyes. The over 50 age group showed trends suggesting a lesser acute migraine attack [35]. Considering our bigger sample of women compared to men in our study, hormonal trigger maybe engorge the role of age in different groups of headache.

We noted a significant difference between age and showing schizophrenia personality trait and also being in guard group. There is some evidence of dopamine receptor activity in migraine and tension type headache [36,37]. Also Dopamine is an inhibitory neurotransmitter involved in the pathology of schizophrenia. The revised dopamine hypothesis states that dopamine abnormalities in the mesolimbic and prefrontal brain regions exist in schizophrenia
$[38,39]$. Further studies with a greater sample size may be needed to confirm any association.

The role of social and environmental stressors may also have a role in the development of schizophrenia and schizophrenia-like psychosis after age 40 [40]. We assumed that our older patients encountered more social and environmental stressors to compare with younger patients. So, it might affect on their schizophrenia trait scales. Any significant association should be assessed by future more powerful studies.

Further studies with a greater sample size may be needed to confirm that.

Our results showed a significant association between depression personality trait and lower educational attainment. In a study in USA showed that those who reported $<16$ years of education had a significantly higher mean BMI (Body Mass Index), were more likely to be obese, were more likely to experience depression, and have a higher mean BID (Body Image Dissatisfaction) score compared to those with $\geq 16$ years of education [41]. Another study suggested cognitive behavioral problem solving therapy or training might be a viable option for reducing levels of stress and depression, and to increase lifesatisfaction in patients suffering from primary headache [42].

The presence of different personality traits in headache patients may need further future studies. Active screening using MMPI in headache patients may identify these personality traits. But personality traits as anxiety and depression should be noted by physicians in headache patients. Also, age and hormonal situation in women can be important to consider.

\section{Acknowledgment}

I would like to thank and give my special regards to deceased doctor Hadi Salary, assistant professor of psychiatry of Golestan University of medical sciences, because of his guide during this project.

\section{References}

1. Stovner L, Hagen K, Jensen R, Katsarava Z, Lipton R, et al. (2007)the global burden of headache: a documentation of headache prevalence and disability worldwide. Cephalalgia 27: 193-210.

2. Pryse-Phillips W, Findlay H, Tugwell P, Edmeads J, Murray TJ, et al. (1992) A Canadian population survey on the clinical, epidemiologic and societal impact of migraine and tension-type headache. Can J NeurolSci 19: 333-9.

3. Leonardi M, Musicco M, Nappi G (1998) Headache as a major public health problem: current status. Cephalalgia18 Suppl 21: 66-9.

4. Leonardi M, Steiner TJ, Scher AT, Lipton RB (2005)the global burden of migraine: measuring disability in headache disorders with WHO's Classification of Functioning, Disability and Health (ICF). J Headache Pain 6: 429-40.

5. Lyngberg AC, Rasmussen BK, Jorgensen T, Jensen R (2005) Incidence of primary headache: a Danish epidemiologic follow-up study. Am J Epidemiol 161: 1066-73.

6. O'Brien B, Goeree R, Streiner D (1994) Prevalence of migraine headache in Canada: a population-based survey. Int J Epidemiol 23: 1020-6.

7. Stewart WF, Lipton RB, Celentano DD, Reed ML (1992) Prevalence of migraine headache in the United States. Relation to age, income, race, and othersociodemographic factors. JAMA 267: 64-9.

8. Jelinski SE, Becker WJ, Christie SN, Giammarco R, Mackie GF, et al. (2006) Demographics and clinical features of patients referred to headache specialists. Can J NeurolSci 33: 228-34. 
9. Edmeads J, Findlay H, Tugwell P, Pryse-Phillips W, Nelson RF, et al. (1993) Impact of migraine and tension-type headache on life-style, consulting behavior, and medication use: a Canadian population survey. Can J NeurolSci 20: 131-7.

10. Bahrami P, Zebardast H, Zibaei M, Mohammadzadeh M, Zabandan N (2012) Prevalence and characteristics of headache in Khoramabad, Iran. Pain Physician 15: 327-32.

11. Arena JG, Blanchard EB, Andrasik F (1984) The role of affect in the etiology of chronic headache. J Psychosom Res 28: 79-86.

12. Bertolotti G, Vidotto G, Sanavio E, Frediani F (2003) Psychological and emotional aspects and pain. NeurolSci24 Suppl 2:S71-5.

13. Chen W, Yu S, Zhu J, Chai H, He W et al. (2012) Personality characteristics of male sufferers of chronic tension-type and cervicogenic headache. J ClinNeurol 8: 69-74.

14. Wittrock DA, Foraker SL (2001) Tension-type headache and stressful events: the role of selective memory in the reporting of stressors. Headache 41: 482-93.

15. Perozzo P, Savi L, Castelli L, Valfre W, Lo Giudice R, et al. (2005) Anger and emotional distress in patients with migraine and tension-type headache. J Headache Pain 6: 392-9.

16. Schmidt FN, Carney P, Fitzsimmons G (1986)an empirical assessment of the migraine personality type. J Psychosom Res 30: 189-97.

17. Silberstein SD, Lipton RB, Breslau N (1995) Migraine: association with personality characteristics and psychopathology. Cephalalgia 15: 358-69.

18. de Leeuw R, Schmidt JE, Carlson CR (2005) Traumatic stressors and post-traumatic stress disorder symptoms in headache patients. Headache 45: 1365-74

19. Sumanen M, Rantala A, Sillanmaki LH, Mattila KJ (2007) Childhood adversities experienced by working-age migraine patients. J Psychosom Res 62: 139-43.

20. Tietjen GE, Brandes JL, Peterlin BL, Eloff A, Dafer RM, et al. (2010) Childhood maltreatment and migraine (part II). Emotional abuse as a risk factor for headache chronification. Headache 50:32-41.

21. Inan L, Soykan C, Tulunay FC (1994) MMPI profiles of Turkish headache sufferers. Headache 34:152-4.

22. Kincannon JC (1968) Prediction of the standard MMPI scale scores from 71 items: the mini-mult. J Consult ClinPsychol 32:319-25.

23. Gayton WF, Bishop JS, Citrin MM, Bassett JS (1975)an investigation of the Mini-Mult validity scales. J Pers Assess 39:511-3.

24. Percell LP, Delk JL (1973) Relative usefulness of three forms of the MiniMult with college students. J Consult ClinPsychol 40:487.

25. Trybus RJ, Hewitt CW (1972) The Mini-Mult in a non-psychiatric population. J ClinPsychol28:371.

26. Sadock BJS, Virginia A, Ruiz Pedro (2009) Neuropsychiatric Aspects of Headache. Kaplan \&Sadock's Comprehensive Textbook of Psychiatry, 9th Edition. 1: Lippincott Williams \& Wilkins 559-60.

27. Folstein MF, Folstein SE, McHugh PR (1975) "Mini-mental state" A practical method for grading the cognitive state of patients for the clinician. J Psychiatr Res 12:189-98.
28. Armentrout JA (1970) Correspondence of the MMPI and Mini-Mult in a college population. J ClinPsychol 26:493-5.

29. Tan HJ, Suganthi C, Dhachayani S, Rizal AM, Raymond AA (2007) The coexistence of anxiety and depressive personality traits in migraine. Singapore Med J 48:307-10.

30. Harold G, Wolff M (1937) Personality features and reactions of subjects with migraine. Arch Neur Psych 37:895-921.

31. Breslau N, Merikangas K, Bowden CL (1994) Comorbidity of migraine and major affective disorders. Neurology 44:S17-22.

32. Breslau N, Andreski P (1995) Migraine, personality, and psychiatric comorbidity. Headache 35:382-6.

33. Aaseth K, Grande RB, Leiknes KA, Benth JS, Lundqvist C, Russell MB (2011) Personality traits and psychological distress in persons with chronic tension-type headache. The Akershus study of chronic headache. ActaneurologicaScandinavica 124:375-82.

34. Pfaffenrath V, HummelsbergerJ, Pollmann W, Kaube H, Rath M (1991) MMPI personality profiles in patients with primary headache syndromes. Cephalalgia 11:263-8.

35. Kelman L (2006) Migraine changes with age: IMPACT on migraine classification. Headache 46:1161-71.

36. Gallai V, Gaiti A, Sarchielli P, Coata G, Trequattrini A, et al. (1992) Evidence for an altered dopamine beta-hydroxylase activity in migraine and tension-type headache. ActaneurologicaScandinavica 86:403-6.

37. Cologno D, Cicarelli G, Petretta V, d'Onofrio F, Bussone G (2008) High prevalence of Dopaminergic Premonitory Symptoms in migraine patients with Restless Legs Syndrome: a pathogenetic link? NeurolSci29 Suppl 1:S166-8.

38. Bauer M, Praschak-Rieder N, Kasper S, Willeit M (2012) Is dopamine neurotransmission altered in prodromal schizophrenia? A review of the evidence. Current pharmaceutical design 18:1568-79.

39. Brisch R, Saniotis A, Wolf R, Bielau H, Bernstein HG, Steiner J, et al. (2014) The role of dopamine in schizophrenia from a neurobiological and evolutionary perspective: old fashioned, but still in vogue. Frontiers in psychiatry 5:47.

40. Sadock BJS, Virginia A, Ruiz Pedro (2009) Schizophrenia and Delusional Disorders. Kaplan \&Sadock's Comprehensive Textbook of Psychiatry, 9th Edition. 2: Lippincott Williams \& Wilkins p. 4076.

41. Gavin AR, Simon GE, Ludman EJ (2010)the association between obesity, depression, and educational attainment in women: the mediating role of body image dissatisfaction. J Psychosom Res 69:573-81.

42. Eskin M,Akyol A, Celik EY, Gultekin BK (2013) Social problem-solving, perceived stress, depression and life-satisfaction in patients suffering from tension type and migraine headaches. Scandinavian journal of psychology 54:337-43. 